\title{
FAKE NEWS COMO AMEAÇA À DEMOCRACIA E OS MEIOS DE CONTROLE DE SUA DISSEMINAÇÃO
}

Vick Mature Aglantzakis ${ }^{1}$

\section{RESUMO:}

O presente artigo tem por objetivo caracterizar as fake news e avaliar a adequação dos métodos de controle para a tutela do sistema democrático brasileiro. Essa análise será feita a partir de uma abordagem qualitativa, fundada no método dialético-crítico, numa perspectiva analítica interdisciplinar. No desenvolvimento, serão apresentadas considerações sobre o acesso à informação e liberdade de expressão como essenciais à democracia. Na sequência, será apresentada a definição de fake news, a difusão da expressão e seus efeitos nas relações em sociedade. Por fim, as fake news serão analisadas como mecanismo de ameaça à democracia, apresentado alguns métodos de controle.

Palavras-chave: Acesso à informação; Fake News; Democracia; Interação social; Liberdade de Expressão.

\section{FAKE NEWS AS A THREAT TO DEMOCRACY AND THE CONTROL MEANS OF ITS DISSEMINATION}

\begin{abstract}
:
This article aims to characterize fake news and evaluate the adequacy of control methods for the protection of the Brazilian democratic system. This analysis will be made from a qualitative approach, based on the dialectical-critical method, from an interdisciplinary analytical perspective. In development, considerations on access to information and freedom of expression will be presented as essential to democracy. Next, the definition of fake news will be presented, the diffusion of the expression and its effects on relationships in society. Finally, the fake news will be analyzed as a mechanism of threat to democracy, presented some methods of control.
\end{abstract}

Keywords: Access to information; Fake News; Democracy; Social interaction; Freedom of speech.

\section{INTRODUÇÃO}

$\mathrm{O}$ avanço tecnológico presenciado no final do século XX e alvorecer do XXI, surpreendeu a todos no mundo inteiro e alterou significativamente o modo como as pessoas têm

\footnotetext{
${ }^{1}$ Mestrando em Prestação Jurisdicional e Direitos Humanos no PPGPJDH da Universidade Federal do Tocantins UFT; Especialista em Direito Civil e Processo Civil pela Universidade Estácio de Sá - UNESA; Graduado em Bacharelado em Direito pela Universidade Federal de Roraima; Técnico Judiciário do Tribunal Regional Eleitoral do Tocantins.
} 
acesso à informação, interagem socialmente e constroem a cultura cívica que possibilita uma efetiva participação democrática de ideias e ações.

O acesso às notícias e a transmissão dos eventos que se sucedem passaram a ocorrer em tempo real ou quase de forma instantânea e a sua disseminação ocorre em curto espaço de tempo. Tudo isso é possível graças à utilização de recursos tecnológicos, especialmente, softwares de troca instantânea de mensagens e a interação nas mídias sociais.

Essa dinâmica da comunicação não passou despercebida pelos grupos políticos, que, nos últimos anos, investiram massivamente na propagação de feitos favoráveis aos seus próceres e desfavoráveis aos que se opõe. Tal característica ficou evidenciada e exposta ao mundo com as eleições presidenciais americanas de 2016 e as eleições brasileiras de 2018, para Presidente da República, Governadores, Senadores, Deputados Federais e Estaduais.

Dessa forma, os instrumentos de comunicação interpessoal que poderiam servir de instrumento para o eleitor/cidadão na escolha consciente de candidatos, políticas públicas e debate democrático, transformaram-se numa arma de guerra sofisticada. Utilizados por agentes de poder, com a disseminação de fake news, acarretaram efeitos nocivos ao processo democrático nacional.

O fenômeno descortinou-se nas eleições norte-americanas de 2016, com impacto substancial, e, como nunca antes visto, nas eleições gerais ordinárias brasileiras de 2018, e tem se propalado mundo afora, como nas eleições na Índia realizadas em 2019.

Se por um lado é difícil avaliar o real impacto das fake news em pleito no qual se decide quais serão os representantes eleitos da comunidade, não menos certo, que o uso desse recurso afronta um dos vetores básicos da sociedade, que é a possibilidade de escolher os seus mandatários com base em conhecimento da verdade, violando frontalmente o próprio instituto da democracia.

Diante disso, o presente artigo, a partir de uma abordagem qualitativa, fundada no método dialético-crítico, numa perspectiva analítica interdisciplinar, tem-se por objetivo central, avaliar alguns métodos de controle das fake news e sua adequação à tutela do sistema constitucional e democrático brasileiro e como tais controles influenciam o processo de construção e consolidação da cidadania. 
Ainda considerando o quadro apresentado, inicialmente serão apresentadas algumas considerações sobre o acesso à informação e a verdade como elementos essenciais à efetivação da democracia. Na sequência buscar-se-á apresentar a definição de fake news destacando o contexto de difusão da expressão e seus efeitos nas relações em sociedade. Por fim, a fake news será analisada como um mecanismo de ameaça à democracia e serão apresentados possíveis métodos de controle.

\section{ACESSO A INFORMAÇÃO E LIBERDADE DE EXPRESSÃO COMO ELEMENTOS ESSENCIAIS À DEMOCRACIA}

O constituinte originário de 1988, já no preâmbulo da Constituição da República Federativa do Brasil, deixou evidente que estava adotando um Estado Democrático, além de, no caput de seu art. $1^{\circ}$, estabelecer que um dos princípios fundamentais da República Brasileira, consiste no Estado Democrático de Direito, buscando, com isso, garantir uma perspectiva ampla de liberdade aos seus cidadãos.

A compreensão do Estado Democrático de Direito perpassa pela noção de democracia. Segundo Bobbio (2002, p.30), democracia, como uma contraproposta a todas as formas de governo autocrático, é caracterizada por um conjunto de regras que estabelece quem está autorizado a tomar decisões coletivas e com quais procedimentos. Essas regras estabelecem quais são os indivíduos autorizados a tomar decisões vinculatórias para todos os membros do grupo e a base de quais procedimentos.

Outra noção fundamental, diz respeito às modalidades de decisão, que na democracia tem como fundamental a regra da maioria. Por fim, Bobbio (2002, p. 32) considera indispensável uma terceira condição: "é preciso que aqueles que são chamados a decidir ou a eleger os que deverão decidir sejam colocados diante de alternativas reais e postos em condições de escolher entre uma e outra". Ou seja, é necessário que se assegure o direito de liberdade de opinião, expressão, de reunião, de associação, direitos à base dos quais foi construída a doutrina do Estado de Direito.

Assim, a democracia é composta de vários elementos que a caracterizam na sociedade ocidental, necessitando de um mínimo de instituições político-democráticas que objetivam respaldá-la perante o corpo social em que está inserida: “a existência de funcionários eleitos; 
eleições livres, justas e frequentes; liberdade de expressão; fontes de informação diversificadas; autonomia para as associações e cidadania inclusiva" (DAHL, 2001, p. 99).

Sobre fontes de informações diversificadas, Dahl (2001, p.100) explica que: "os cidadãos têm o direito de buscar fontes de informação diversificadas e independentes de outros cidadãos, especialistas, jornais, revistas, livros, telecomunicações e afins”.

No plano normativo, a Constituição Federal brasileira, assegura no art. 5, XIV, que "é assegurado a todos o acesso à informação e resguardado o sigilo da fonte, quando necessário ao exercício profissional". Trata-se de um direito e uma garantia fundamental, destinados a brasileiros e estrangeiros que se encontram no território nacional.

Considerando que a consolidação e o desenvolvimento da democracia dependem da existência da liberdade de expressão, o Brasil é signatário da Declaração de Chapultepec, de 1994, sobre a liberdade de expressão e de imprensa, aprovada pela Comissão Interamericana de Direitos Humanos, que estatui em seu primeiro princípio, que: "I -Não há pessoas nem sociedades livres, sem liberdade de expressão e de imprensa. O exercício dessa não é uma concessão das autoridades; é um direito inalienável do povo" (OEA, 2019A).

De igual forma dispõe a Declaração de Princípios sobre a Liberdade de Expressão, que entende que a liberdade de expressão não é uma concessão dos Estados, e sim, um direito fundamental, conforme seus princípios insculpidos nos itens 1 e 2 que:

1. A liberdade de expressão, em todas as suas formas e manifestações, é um direito fundamental e inalienável, inerente a todas as pessoas. É, ademais, um requisito indispensável para a própria existência de uma sociedade democrática.

2. Toda pessoa tem o direito de buscar, receber e divulgar informação e opiniões livremente, nos termos estipulados no Artigo 13 da Convenção Americana sobre Direitos Humanos. Todas as pessoas devem contar com igualdade de oportunidades para receber, buscar e divulgar informação por qualquer meio de comunicação, sem discriminação por nenhum motivo, inclusive os de raça, cor, religião, sexo, idioma, opiniões políticas ou de qualquer outra índole, origem nacional ou social, posição econômica, nascimento ou qualquer outra condição social" (OEA, 2019B).

O Supremo Tribunal Federal ${ }^{2}$ tem se posicionado no sentido de que um dos vetores mestres da democracia é o exercício da liberdade de expressão, vez que constitui condição

\footnotetext{
${ }^{2}$ LIBERDADE DE EXPRESSÃO E PLURALISMO DE IDEIAS. VALORES ESTRUTURANTES DO SISTEMA DEMOCRÁTICO. INCONSTITUCIONALIDADE DE DISPOSITIVOS NORMATIVOS QUE ESTABELECEM PREVIA INGERÊNCIA ESTATAL NO DIREITO DE CRITICAR DURANTE O PROCESSO ELEITORAL. PROTEÇÃO CONSTITUCIONAL AS MANIFESTAÇÕES DE OPINIÕES DOS MEIOS DE COMUNICAÇÃO E A LIBERDADE DE CRIAÇÃO HUMORISTICA. “...omissis...” (ADI 4451,
} 
fundamental ao pluralismo de ideias. Assim, a livre discussão, a extensa participação política e o princípio democrático são diretamente ligados à liberdade de expressão de pensamentos e ideias, opiniões, crenças, realização de juízo de valor e críticas a agentes públicos, no sentido de garantir a real participação dos cidadãos na vida coletiva.

A democracia, enquanto sistema de governo, não se destina apenas à maioria, mas também para proteger o dissenso da minoria, possibilitando o debate plural, tanto no espaço público quanto no espaço privado, assegurando a pluralidade de ideias, das formas de ser, de informar e ser informado pelo meio que convier.

Assim, o acesso à informação e a liberdade de expressão constituem-se como instrumentos fundamentais à efetivação de um sistema democrático e ao fortalecimento do exercício da cidadania.

Nos dias atuais, no contexto da denominada sociedade da informação, as pessoas contam com uma diversidade imensa de meios para efetivar o direito à liberdade de expressão e acesos à informação, especialmente em ambiente eletrônico. As novas tecnologias permitem que pessoas e grupos sociais se conectem, ampliando as formas de obter e compartilhar informações, de relacionar entre si, de se manifestar e entender a realidade.

Diante da difusão de recursos tecnológicos, de canais de comunicação e divulgação de informação, como as mídias sociais, o Governo Federal, no ano de 2016, através da Secretaria Especial de Comunicação Social da Presidência da República, publicou a Pesquisa Brasileira de Mídia (BRASIL, 2016, p.48), em que quase a metade dos entrevistados (49\%) mencionou em primeiro ou em segundo lugar a rede mundial de computadores como meio para "se informar mais sobre o que acontece no Brasil", alterando substancialmente o modo como se consume informações.

Ainda sobre o uso de recursos tecnológicos para acessar a internet e redes sociais, na Pesquisa Brasileira de Mídia (BRASIL, 2016, p.64), 91\% dos entrevistados utilizam o aparelho celular como dispositivo de acesso à internet e ainda cerca de $15 \%$ confiam sempre ou muitas vezes nas notícias que circulam nas redes sociais e $63 \%$ confiam poucas vezes nas notícias que circulam nas redes sociais.

Relator(a): Min. ALEXANDRE DE MORAES, Tribunal Pleno, julgado em 21/06/2018, PROCESSO ELETRÔNICO DJe-044 DIVULG 01-03-2019 PUBLIC 06-03-2019) 
Tais números demonstram o alcance que a comunicação digital e a interação com as mídias sociais possuem no Brasil, transformando-se em um espaço não somente de interação, mas de acesso a informações e notícias sobre o mundo que as circunda.

Esse quadro põe em destaque os meios digitais como importante instrumento não somente para a comunicação, mas para o exercício do direito de liberdade de expressão, que é pressuposto do Estado Democrático de Direito.

Considerando que o acesso à informação e a liberdade de expressão são consectários da democracia, já que repercutem diretamente sobre a tomada de decisão dos cidadãos, é necessário refletir sobre os artifícios utilizados por meio da linguagem para influenciar alguém a adotar determinado comportamento.

O ambiente democrático, demanda um processo comunicativo pautado em diálogos claros. Assim, a exigência por verdade figura como requisito essencial ao exercício pleno da democracia, de forma que o povo não tem condições de governar ou de ter acesso efetivamente ao poder se é induzido a decidir fundado no engano (NEISSER; BERNARDELLI; MACHADO, 2018, p.51).

Hans-Georg Gadamer (2002, p. 60) ao buscar a definição de verdade, a considera como desocultação: "o sentido do discurso é deixar e fazer com que o desocultado se apresente, se revele. Alguém apresenta algo, que desse modo está ali comunicado ao outro, do mesmo modo que está para este primeiro". Dessa forma, quanto ao juízo que se forma, ele será verdadeiro quando propõe uma reunião do que está reunido com a coisa. Será um juízo falso quando deixa e propõe uma reunião no discurso daquilo que não está reunido na coisa. A verdade do discurso será determinada como adequação do discurso à coisa (GADAMER, 2002, p. 60-61).

Nesse sentido, quando se destaca a liberdade de expressão e o acesso à informação como garantias fundamentais ao exercício da democracia em uma sociedade de informação, movida por recursos tecnológicos que tornam mais ágeis não somente o diálogo entre as pessoas, mas, também, o trânsito de conteúdo entre elas, é essencial que se considere que tais garantias asseguradas em um Estado Democrático de Direito podem ser afetadas com a utilização de recursos e artifícios que comprometam a interação interpessoal gerando desinformação e manipulação do debate público. 


\section{NOÇÕES CONCEITUAIS SOBRE FAKE NEWS}

O fenômeno das fake news, ou o uso de notícias falsas divulgadas por meio da internet não é recente, mas se tornou popular em meados da presente década. Notícias falsas relacionadas a questões de interesse público sempre foram disseminadas, especialmente diante de embates políticos. É possível afirmar que desde o surgimento da impressa escrita e outras formas de difusão de informações, fatos são modificados, ampliados, reduzidos ou descontextualizados visando gerar certas reações e comportamentos do público.

Recentemente, o evento que contribuiu para uma maior difusão do uso do termo fake news no espaço público foi a candidatura e posterior vitória de Donald Trump à Presidência dos Estados Unidos da América (EUA) (CARDOSO et al, 2018, p. 15). Outro acontecimento, ocorrido com alguma proximidade temporal, foi o Brexit. Foi em grande parte por causa desses processos que surgiu com maior força a ideia de fake news e de uma sociedade afetada pela propagação de falsas notícias, já que tais eleições parecem ter sido marcadas pela disseminação deliberada de informação de alguma forma manipulada ou inverídica, acompanhada sempre por um discurso de natureza populista (CARDOSO et al, 2018, p. 15-16).

A virtualização dos relacionamentos sociais, aliada à facilidade de uso de mecanismos de direcionamento de mensagens e com a redução de custos para produzir e divulgar os mais variados tipos de conteúdo deram dimensão inédita ao problema (BLIKSTEIN; FERNANDES; COUTINHO, 2018, p. 22).

A quantidade de pessoas que podem ser atingidas ou influenciadas e a velocidade com que o fenômeno ocorre ficam muito além da capacidade reguladora do Estado ou coercitiva de qualquer organização da sociedade.

A eficiência das fake news em gerar mudanças de comportamento concretas (no processo eleitoral, por exemplo) ainda é discutível e avaliada no conjunto do eleitorado como um todo, mas pode ser altamente eficaz para reforçar crenças e preconceitos, especialmente com os mecanismos de direcionamento de conteúdo utilizados pelas redes sociais (BLIKSTEIN; FERNANDES; COUTINHO, 2018, p. 22). 
David O. Klein e Joshua R. Wueller (2017) definem "fake news" "as the online publication of intentionally or knowingly false statements of fact ${ }^{\prime 3}$. Trata-se de uma falsidade elaborada, manipulada para não corresponder à verdade. O intuito das fake news é o de criar ideias no imaginário coletivo e provocar determinadas reações da sociedade, de modo a possibilitar vantagem a algum indivíduo ou grupo social.

Os problemas derivados das fake news não se efetivam somente através de meios de comunicação de massa ou de autoritarismo, mas também num cenário digital e de democracia. Com a Internet foram estabelecidas as condições tecnológicas para o surgimento de uma sociedade que se comunica em rede, gerando um espaço de expressão livre onde qualquer informação pode ser produzida, transmitida e recebida.

Por diversas vezes, essa prática desinforma e confunde as pessoas que, sem os instrumentos e o acesso para checar a veracidade das informações que recebem, tem na imprensa seu vetor de confiança. Nas redes sociais, essa credibilidade vem de conhecidos, amigos e familiares.

Outro não é o pensamento de Aloysio Nunes quando afirma que fake news não podem ser denominadas simplesmente de mentiras, pois elas misturam informações verdadeiras e falsas suscetíveis de persuadir o leitor: sendo assim, parecem notícias, têm aspectos de notícias, mas não são notícias. "São, na realidade, meias verdades” (NUNES, 2018).

Claire Wardle (2017), pesquisadora da Universidade de Harvard, destaca que a definição de fake news, ultrapassa a noção de notícias falsas, é na verdade um ecossistema de informações, muito mais amplo que a noção de informação incorreta (mis-information ${ }^{4}$ ) e de desinformação (dis-information ${ }^{5}$ ).

Para Wardle (2017), fake news é um ecossistema de informações em que três elementos devem ser considerados: a) os diferentes tipos de conteúdo que são criados e

\footnotetext{
${ }^{3}$ Tradução livre: Como a publicação on-line que apresenta fato intencionalmente ou conscientemente falso. ${ }^{4}$ Para a autora, mis-information significa informação incorreta, sem que haja a intenção dolosa de causar dano (WARDLE, 2017).

${ }^{5}$ Dis-information ocorre a partir da publicação de informação enviesada, com a adulteração de informações e manipulação de conteúdo (WARDLE, 2017).
} 
compartilhados; b) as motivações de quem cria esse conteúdo; c) a forma como o conteúdo é disseminado.

Em relação aos tipos de conteúdo que são criados pode-se destacar diversos tipos de informações falsas ou desinformações como: sátiras, informações com parte do conteúdo omitido, informações totalmente falsas, informações apresentadas dentro de um contexto falso, informações com conteúdo manipulado, dentre outras (WARDLE, 2017).

Quanto as motivações de quem cria o conteúdo temos: jornalismo pobre, paródia, provocação, paixão, partidarismo, lucro, influência política ou poder e propaganda.

A forma como o conteúdo é disseminado agrava ainda mais o efeito das fake news de influenciar a opinião pública, visto que, no lugar de se utilizar de tecnologias que transmitiam a informação de um sujeito para muitos, temos o sistema das redes sociais que possibilitam que "átomos" de propaganda sejam diretamente direcionados a usuários com maior probabilidade de aceitar e compartilhar um conteúdo. Assim, esses "átomos" são disparados por meio do ecossistema de informações em alta velocidade, alimentados por redes confiáveis ponto a ponto (WARDLE, 2017).

Partindo desse ecossistema é possível definir fake news como informações incorretas ou falsas disseminadas em grande escala, especialmente por redes sociais, com o intuito de gerar consensos sociais e influenciar processos de tomada de decisão, prejudicando ou beneficiando determinadas pessoas ou grupos sociais (BOQUADY, 2018, p.49).

Como se depreende dos conceitos acima ilustrados e da utilização da expressão por diversos países (PHILIP, 2019), a expressão fake news, já é largamente utilizada, não obstante ser de recente uso na história mundial, tem um efeito mais danoso que a notícia falsa, que justifica o uso corrente da expressão anglicana. Ela se reveste de características que permitem a sedução do leitor, pois vai ao encontro do sentimento que ele projeta em sua consciência, ou seja, abriga os que compartilham do mesmo ideal.

A divulgação das fake news, são elaboradas e sofisticadas, pois são geradas e replicadas por computadores, bots $^{6}$ e robôs com base em dados disponíveis nas mídias sociais e

\footnotetext{
${ }^{6}$ Bot pode ser definido como um programa de computador fabricado para automatizar procedimentos, geralmente repetitivos, que facilitam a execução de tarefas antes realizadas por aplicativos, sem a necessidade de utilizar a interface de um aplicativo específico (LOUREIRO, 2016).
} 
aplicativos de interação social, transformando a informação em um produto onde transmitir narrativas não condizentes com a verdade factual, principalmente as que distorcem o discurso político e econômico, tem atendido aos objetivos de determinados sujeitos ou grupos sociais.

O cenário exposto direciona uma atenção especial com o uso que se confere às redes sociais, que estão sendo utilizadas, sob a proteção da liberdade de expressão, para propalar falsas notícias, na intenção de causar impacto no poder de decisão do povo.

Preocupa a advertência trazida por Deibert, quando afirma que diante da enxurrada de informações a que são expostos os usuários de aplicativos e interações sociais, as pessoas acabam se acomodando na zona de conforto das opiniões que elas compartilham e entendem como verdadeiras, sem averiguação da veracidade do teor veiculado. E segue: “o próprio algoritmo das redes sociais coloca os usuários em bolhas online, nas quais se sentem confortáveis e ideologicamente alinhados" (DEIBERT, 2019, p.37).

A história reporta diversos casos de notícias falsas, que podem acarretar atos de violência como numa situação noticiada pelo site da BBC, no ano de 2018 , que na cidade de Acatlán, situada no México, dois homens, sobrinho e tio, foram linchados e queimados por uma multidão, em virtude de boatos divulgados no WhatsApp, com os seguintes dizeres: "por favor, estejam todos atentos porque uma praga de sequestradores de crianças entrou no país" e "parece que esses criminosos estão envolvidos com o tráfico de órgãos. Nos últimos dias crianças de quatro, oito e 14 anos desapareceram e algumas foram encontradas mortas com sinas de que seus órgãos foram removidos". A turba enfurecida, adentrou a delegacia onde os dois estavam, por suposta violação do sossego público, e, sem que ninguém verificasse a verdade do teor divulgado, mataram os mesmos, havendo até quem pedisse dinheiro para comprar gasolina para atear fogo. Os atos criminosos foram divulgados em tempo real através do facebook (MARTINEZ, 2018).

Por tudo que foi exposto, pode-se definir fake news como notícias sabidamente inverídicas, propagáveis, massificadas, que viralizam num tempo recorde, sob aparente proteção da liberdade de expressão e acesso à informação, garantidas constitucionalmente.

\section{FAKE NEWS COMO AMEAÇA À DEMOCRACIA E ALGUMAS SOLUÇÕES PARA CONTROLAR SUA DISSEMINAÇÃO}


As repercussões das fake news, foram amplamente discutidas no julgamento proferido na ADI 4451/DF, proposta pela Associação Brasileira de Emissoras de Rádio e Televisão (Abert) contra os incisos II e III (em parte) do artigo 45 da Lei das Eleições (Lei 9.504/1997).

A referida Ação Direita de Inconstitucionalidade foi julgada procedente por unanimidade em 21/06/2018 considerando inconstitucionais os incisos II e III do artigo $45^{7}$ da Lei das Eleições. No referido julgamento, muito embora, tenha sido ressaltado o risco das fake news para o processo eleitoral, prevaleceu o juízo de que é violação à liberdade de expressão estabelecer uma censura prévia de caráter preventivo e abstrato, de um conteúdo que se pretende expressar, até mesmo porque a ordem jurídica dispõe de mecanismos para responsabilizar os autores por eventuais informações injuriosas, difamantes, mentirosas, e em relação a eventuais danos materiais e morais, pois os direitos à honra, intimidade, vida privada e à própria imagem formam a proteção constitucional à dignidade da pessoa humana (BRASIL, 2018, p.21).

Por outro lado, restou clara a preocupação com a difusão das fake news para a democracia. O Ministro Luiz Fux (BRASIL, 2018, p. 71), no julgamento da ADI 4451/DF, destacou que no processo democrático há a necessidade da lisura informacional tendo em vista que o voto somente é livre se não for maculado por suborno, corrupção e desinformação.

Dada a importância do tema, O Conselho Nacional dos Direitos Humanos aprovou por seu plenário, na 38 ${ }^{\mathrm{a}}$ Reunião Ordinária, ocorrida entre 11 e 13 de junho de 2018, a Recomendação $\mathrm{n}^{\circ}$ 04/2018, com o objetivo de sugerir medidas ${ }^{8}$ de combate às fake news e a

\footnotetext{
${ }^{7}$ Art. 45. Encerrado o prazo para a realização das convenções no ano das eleições, é vedado às emissoras de rádio e televisão, em sua programação normal e em seu noticiário:

$[\ldots]$

II - usar trucagem, montagem ou outro recurso de áudio ou vídeo que, de qualquer forma, degradem ou ridicularizem candidato, partido ou coligação, ou produzir ou veicular programa com esse efeito;

III - veicular propaganda política ou difundir opinião favorável ou contrária a candidato, partido, coligação, a seus órgãos ou representantes;

${ }^{8}$ Recomenda: Ao Congresso Nacional - A aprovação, pelo Senado Federal, do PLC no 53/18, já votado na Câmara dos Deputados em maio de 2018, que traz as bases para uma efetiva proteção no tratamento de dados pessoais no Brasil. - A aprovação de iniciativas legislativas, para combater o tema das "notícias falsas", que respeitem os padrões internacionais de direitos humanos, à liberdade de expressão e informação e que promovam a diversidade na internet por meio do fortalecimento da comunicação plural, diversa e qualificada, ao invés de legislar com enfoque na lógica de criminalização dos usuários que compartilham essas notícias. Além disso, qualquer legislação sobre o tema deve conter também, de maneira clara, os mecanismos de apelo que o denunciado, por compartilhar conteúdo falso, pode recorrer para contestar as acusações e comprovar a veracidade do conteúdo difundido.
} 
garantia do direito à liberdade de expressão ao Congresso Nacional, ao Tribunal Superior Eleitoral, ao Executivo Federal e Estaduais e às plataformas privadas.

A própria alteração dos fatos, próximos da realidade com o nítido objetivo de causar estados de comoção ou euforia, angariar simpatizantes e fomentar o discurso de ódio, revela-se em nítido perigo ao próprio conceito de democracia, o qual convive com o dissenso da minoria.

No plano do controle das fake news, para Gustavo Cardoso e outros (2018), é possível identificar três possibilidades que decorrem: da atuação do Poder Legislativo, ao criar leis que impõe sanções a tais práticas; das redes sociais ao criarem mecanismos de verificação do conteúdo disseminado em suas páginas ou aplicativos virtuais, mediante um marco regulatório; e, num plano mais amplo de atuação e análise, ver as fake news como uma questão social, onde os atores, no caso a sociedade, devem optar por suas escolhas e responsabilidade (CARDOSO et al, 2018, p. 7-8).

O Ministro do STF Luiz Fux, no julgamento da ADI 4451/DF, considera que, a tutela jurídica que é prevista na lei hoje, se estabelece de forma que o princípio da inafastabilidade prevê medidas preventivas e repressivas. No âmbito civil, temos o dano moral e a responsabilidade civil; no âmbito criminal, com os crimes contra a honra, praticados na seara

Ao Tribunal Superior Eleitoral - A adoção dos parâmetros de direitos humanos à liberdade de expressão e informação como orientadores para todas as medidas a serem elaboradas pelo Conselho Consultivo sobre Internet e Eleições, (composto por órgãos como a Polícia Federal e a Agência Brasileira de Inteligência (Abin)), para que não sejam consideradas as vias da criminalização e do tratamento policial como formas de enfrentamento às questões relativas ao compartilhamento de "notícias falsas".

Ao Executivo Federal e Estaduais - A adoção de políticas públicas de Alfabetização Midiática e Informacional (Media and Information Literacy - MIL) e a promoção de práticas de empoderamento digital, nas quais se inclui o fomento à produção de conteúdos positivos e contra-narrativas que engajem a sociedade num debate mais qualificado balizado pelo respeito aos direitos humanos e aos princípios de pluralidade e diversidade, conforme recomenda a Unesco. - Que estimulem - por meio de campanhas e iniciativas de educação para a mídia - os cidadãos e cidadãs a exigir o direito de resposta ou a retificação do ofendido em matéria divulgada, publicada ou transmitida por veículo de comunicação social, conforme regulamentado na Lei $n^{\circ}$ 13.188/2015. - Adoção de políticas públicas voltadas à realização de educação não formal no que tange a "Educação e Mídia", um dos eixos de atuação do Plano Nacional de Educação em Direitos Humanos (instituído pela Portaria 66 de 12 de maio de 2003), o qual o Estado Brasileiro deve realizar e estimular o cumprimento, buscando a promoção da cultura de paz e direitos humanos, por meio de um ambiente digital mundial mais aberto e livre e de respeito, promoção e proteção de direitos.

Às plataformas privadas (Facebook, Twitter e Google) - A adoção de políticas que garantam transparência sobre o seu funcionamento e as regras das suas comunidades e que ampliem o controle dos usuários sobre os conteúdos que publicam e acessam, incidindo sobre o chamado efeito bolha e a estrutura de monetização que estimula a criação e difusão das chamadas "notícias falsas". Além do respeito às normas infralegais e internacionais em matéria de direitos humanos e a adequação das políticas das plataformas às especificidades sociais e culturais dos países onde gerem seus modelos de negócios (BRASIL, 2018A). 
eleitoral; ainda no plano eleitoral, há o tipo aberto do art. 323 do Código Eleitoral, trata justamente da propaganda massiva enganosa; também há, sem prejuízo, medidas administrativas, multas por propaganda irregular, direito de resposta e até cassações de mandato por abuso de poder, caso o financiamento das fake news for engendrado por pessoa jurídica; e por fim, o art. 222 do Código Eleitoral prevê a possibilidade de anulação de uma dada eleição de determinado candidato, se essa resultou da influência da propaganda massiva enganosa (BRASIL, 2019, p. 71-72).

Considera-se, assim, que não cabe ao Estado brasileiro implementar medidas de controle prévio sobre o que cada cidadão, no debate político, econômico, social, entre outros, possa publicar nas redes sociais ou compartilhar em aplicativos de mensagens instantâneas.

É inegável que em virtude do alcance que as redes possuem há uma responsabilidade pessoal, onde cada cidadão é responsável pela guarda dos valores democráticos e da própria democracia, sendo que a ordem jurídica vigente possui meios de responsabilizar os autores pelas consequências decorrentes da publicação de fake news, vez que é próprio de um sistema que defende os direitos humanos e o próprio conceito de democracia, a salvaguarda das liberdades e, em especial nesse contexto, as liberdades de manifestação, opinião, divulgação e replicagem de mensagens verdadeiras ou não.

A imposição de censura que cerceia a liberdade de informação, de expressão e de pensamento é inadmissível na ordem constitucional vigente, sendo própria de regimes políticos que não admitem a manifestação de minorias e de expressão do seu pensar.

A orientação acima é comungada pelo Pretório Excelso, nos termos da passagem do voto do Ministro Celso de Mello, por ocasião do julgamento da ADI 4451/DF, que defende a livre criação de ideias, sem barreiras que a obstaculizem:

É por isso que se impõe construir espaços de liberdade, em tudo compatíveis com o sentido democrático que anima nossas instituições políticas, jurídicas e sociais, para que o pensamento não seja reprimido e, o que se mostra fundamental, para que as ideias possam florescer, sem indevidas restrições, em um ambiente de plena tolerância, que, longe de sufocar opiniões divergentes, legitime a instauração do dissenso e viabilize, pelo conteúdo argumentativo do discurso fundado em convicções antagônicas, a concretização de valores essenciais à configuração do Estado democrático de direito: o respeito ao pluralismo político e à tolerância (BRASIL, 2019, p. 136). 
O povo que não debate transforma-se numa massa de pessoas em que nenhum indivíduo exterioriza seu pensamento, perde a sua natureza humana e transforma-se em uma coisa, pois, é próprio da vida, o pensamento antagonista, que permite a discussão e abertura para possibilidades, longe do extremismo, que pode acarretar em um ato irresponsável, uma democracia degenerativa (ZAGREBELSKY, 2011, p.123-126).

A democracia, enquanto regime político está em permanente estado de construção, flexibilização e aceitação das mais diversas formas de manifestação, de forma a distensionar a tensão natural de um regime que não permita a discussão de ideias, o respeito a valores mínimos como as diversas liberdades encampadas na Constituição Federal, o debate aberto no espaço público, sobretudo que afeta o próprio Estado brasileiro e seja de interesse dos cidadãos em questionar, debater e até mesmo apontar e sugerir soluções.

Não se pode permitir a produção de fake news, de forma a comprometer a convivência social, a deturpar a verdade, que leve a maioria a eleger alguém com base em fatos inverídicos, pois não será a vontade da maioria que estará se manifestando e, sim, uma vontade manipulada, não condizente com o próprio conceito de democracia.

Para tanto, faz-se necessária a adoção de uma democracia crítica, como pretende Zagrebelsky (2011, p.132), onde as diversas possibilidades devem estar permanentemente à disposição de todos, dentro das possibilidades permitidas e onde é "função de si mesma", não cabendo a arrogância em si, que não aceita inquietação, mudanças e adaptações.

\section{CONCLUSÃO}

As notícias manipuladas não somente podem interferir sobre a compreensão da realidade, mas tem o condão de colocar em risco a democracia, enquanto concebida a vontade da maioria, em detrimento da minoria, sem olvidar o respeito às mesmas.

Não obstante a possibilidade da manipulação na tomada de decisão por determinado grupo social seja próprio da democracia, e talvez seja esta a sua maior virtude, o respeito às liberdades individuais, e no que toca ao presente tema, a liberdade de defender suas convicções, informar o que acredita ser verdade, ou seja, permitir o amplo espaço do debate de ideias, de criação e de participação, deve ser buscado sempre. 
As formas de controle formal através da produção legislativa, do controle exercido pelo Poder Judiciário ou pelas empresas, através de software de verificação do conteúdo divulgado são apenas algumas medidas a serem tomadas. Essas podem não se mostrar as mais acertadas e, em alguns momentos, especialmente, se figurar como uma espécie de censura prévia, incabível em um Estado que se proclama como democrático, Estado este que tem posicionamento firme da Excelsa Corte, conforme visto na ADI 4451/DF, e que consta também no julgado da ADPF $\mathrm{n}^{\mathrm{o}} 130$, contrariamente aos controles prévios, devendo estes agente de controle direto e/ou indireto se atentarem a tais premissas.

Ademais, há de se considerar que todo ecossistema de informação, a internet, a difusão das redes sociais, a utilização de mecanismos como robôs para potencializar a difusão da notícia falsa, dificulta sobremaneira o controle das fake news, levando os agentes de controle a uma tendência de controle antecedente.

A tentação pelo controle, de forma a evitar um possível caos gerado por uma fake news, é uma tendência natural, contudo o seu uso transbordaria para uma ditadura da informação, onde só seria veiculado o que interessasse ao Estado ou a determinado segmento social, ampliando um instrumento de controle das ideias, das informações e da liberdade de expressão, gerando, com isso, um efeito, talvez até mais grave, de manipulações do que poderia ou não ser difundido entre o meio social.

Como participantes da democracia brasileira, cabe a seu povo a colaboração na defesa da democracia e dos valores que esta irradia, a fim de que falsas verdades não mascarem uma falsa maioria, principalmente onde a participação social seria nula ou quase nula.

Não se pode vendar os olhos para o fenômeno da massificação das informações como produto apto a formar uma maioria, através de instrumentos tecnológicos como bots e robôs que fomentam a discussão e disseminam determinado tema de acordo com as preferências colhidas nos aplicativos destinados às redes sociais, de forma a angariar a simpatia do usuário, com base nas informações obtidas através de algoritmos.

Tampouco a demonização é cabível. Cabe maior responsabilidade no uso dos aplicativos de mensagens e redes sociais por parte dos usuários, sempre com um pensamento voltado para o lado crítico, a questionar com que intuito dado conteúdo é veiculado e fazer a sua própria validação. Isto é exercer a democracia de maneira mais forte, questionar, debater e 
chegar à conclusão realmente esclarecida que se alinhe aos seus valores e aos fatos que lhe deram origem.

\section{REFERÊNCIAS}

BLIKSTEIN, Izidoro; FERNANDES, Manoel; COUTINHO, Marcelo. Fake news no mundo corporativo. GV EXECUTIVO, [S.1.], v. 17, n. 5, p. 22-25, out. 2018. ISSN 1806-8979. Disponível em:

<http://bibliotecadigital.fgv.br/ojs/index.php/gvexecutivo/article/view/77337/74184>. Acesso em: 29 Jun. 2019. doi:http://dx.doi.org/10.12660/gvexec.v17n5.2018.77337.

BOBBIO, Norberto. O Futuro da Democracia. 8. ed. Tradução de Marco Aurélio Nogueira. Rio de Janeiro: Paz e Terra, 2002.

BOQUADY, Natália Ribeiro Levy. Democracia e internet: os impactos das mídias digitais nas eleições gerais de 2018. (Monografia). Brasília: Universidade de Brasília. Faculdade de Direito, 2018.

BRASIL. Ministério de Direitos Humanos. Conselho Nacional dos Direitos Humanos.

Resolução n. 4, de 11 de junho de 2018. Recomenda sobre medidas de combate às fake news (notícias falsas) e a garantia do direito à liberdade de expressão. Disponível em:

https://webcache.googleusercontent.com/search?q=cache:_Yf3JXJeWqoJ:https://www.mdh.go v.br/informacao-ao-cidadao/participacao-social/recomendacao-ndeg-04-2018_fake-news-eliberdade-de-expressao.pdf $+\& \mathrm{~cd}=2 \& \mathrm{hl}=\mathrm{pt}-\mathrm{BR} \& \mathrm{ct}=\mathrm{clnk} \& \mathrm{gl}=$ br. Acesso em: 02.04.2020.

Presidência da República. Secretaria Especial de Comunicação Social. Pesquisa

Brasileira de Mídia 2016: hábitos de consumo de mídia pela população brasileira. - Brasília : Secom, 2016. Disponível em: http://secom.gov.br/atuacao/pesquisa/lista-de-pesquisasquantitativas-e-qualitativas-de-contratos-atuais/pesquisa-brasileira-de-midia-pbm-20161.pdf/view. Acesso em 26.06.2019.

Supremo Tribunal Federal. Ação Direita de Inconstitucionalidade n. 4451/DF Distrito Federal. Requerente: Associação Brasileira de Emissoras de Rádio e Televisão ABERT. Relator: Ministro Alexandre de Moraes. 21 jun. 2018. Disponível em: http://portal.stf.jus.br/processos/downloadPeca.asp?id=15339639568\&ext=.pdf. Acesso em: 29.06.2019.

CARDOSO, Gustavo; BALDI, Vania; PAIS, Pedro; PAISANA, Miguel; QUINTANILHA, Tiago; COURACEIRO, Paulo. As fake news numa Sociedade Pós-Verdade:

Contextualização, potenciais soluções e análise. In: Observatório da Comunicação, Lisboa, Portugal. Junho de 2018. Disponível em: https://obercom.pt/wp-content/uploads/2018/06/2018Relatorios-Obercom-Fake-News.pdf. Acesso em: 29.06.2019.

CHAUI, Marilena. Convite à filosofia. 6. ed., São Paulo: Ática, 1995. 
DAHL, Robert A. Sobre a democracia. Tradução de Beatriz Sidou. Brasília: Editora Universidade de Brasília, 2001.

DEIBERT, Ronald J. Três Duras Verdades Sobre as Redes Sociais. In: Journal of Democracy. maio 2019, v. 08, n. 01,p. 27-50. Disponível em:

http://www.plataformademocratica.org/Arquivos/JD-

v8_n1_02_O_caminho_para_a_falta_de_liberdade_digital.pdf. Acesso em: 29.06.2019.

Editora Universidade de Brasília, 2001.

GADAMER, Hans-Georg. Verdade e Método II: traços fundamentais de uma hermenêutica filosófica. 2.ed. Petrópolis: Editora Vozes, 2002.

KLEIN, David O.; WUELLER, Joshua R. Fake News: A Legal Perspective. In: Journal of Internet Law. Apr2017, Vol. 20 Issue 10, p1-13. 9p.

LOUREIRO, Rodrigo. Entenda de uma vez por todas o que é um bot e como ele funciona. In: Olhar Digital. 11 abr. 2016. Disponível em: https://olhardigital.com.br/noticia/entenda-deuma-vez-por-todas-o-que-e-um-bot-e-como-ele-funciona/57075. Acesso em: 01.04.2020.

MARTINEZ, Marcos. Como as 'fake news' no WhatsApp levaram um povoado a linchar e queimar dois homens inocentes. In: BBC: News: Brasil.14 nov. 2018. Disponível em: https://www.bbc.com/portuguese/salasocial-46206104. Acesso em: 12.12.2019.

NUNES, Aloysio. Fake news são 'meias verdades'. In: ASSOCIAÇÃO NACIONAL DE JORNAIS. Disponível em: https://www.anj.org.br/site/cartilha/97-midia-nacional/10014-fakenews-sao-meias-verdades.html. Acesso em 20.05.2019.

NEISSER, Fernando; BERNADELLI, Paula; MACHADO, Raquel. A mentira no ambiente digital: impactos eleitorais e possibilidades de controle. In: Tratado de Direito Eleitoral Volume 4 - Propaganda Eleitoral. FUX, Luiz; PEREIRA, Luiz Fernando Casagrande; AGRA, Walber de Moura (coord.); PECCININ, Luiz Eduardo (org.). Belo Horizonte: Fórum, 2018.

ORGANIZAÇÃO DOS ESTADOS AMERICANOS (OEA). Declaração de Chapultepec, 1994 sobre a liberdade de expressão e de imprensa. Disponível em:

www.direitoshumanos.usp.br/index.php/Documentos-não-Inseridos-nas-Deliberações-daONU/declaracao-de-chapultepec-1994.html. Acesso em: 26.06.2019.

Declaração de Princípios Sobre Liberdade de Expressão. 2000. Disponível em: http://oas.org/pt/cidh/expressao/showarticle.asp?artID=26\&lID=4. Acesso em: 26.06.2019.

PHILIP, Bruno. L'Indonésie à l'heure des « fake news » électorales. In: Le monde: international: Indonésie. 15 abr. 2019 Disponível em:

https://www.lemonde.fr/international/article/2019/04/15/l-indonesie-a-l-heure-des-fake-newselectorales 5450327 3210.html?xtmc=fake_news\&xtcr=32. Acesso em 03.04.2020. 
WARDLE, Claire. Fake News. It's complicated. In: First Draft. Medium. 16 fev. 2017. Disponível em: <https://medium.com/1st-draft/fake-newsits-complicated-d0f773766c79>. Acesso em: 25.10.2019.

ZAGREBELSKY, Gustavo. A Crucificação e a Democracia. São Paulo: Saraiva, 2011. 